\title{
Making space for past futures: rural landscape temporalities in Roman Britain
}

\begin{abstract}
In this paper, we seek to explore the ways in which landscapes become venues not only for manipulations of the past in a present, but also for shaping possible futures. Considerations of temporality and being in the landscape have been more strongly focussed on the past and social memory than the future, anticipation, and projectivity, but these are vital considerations if we are to preserve the possibility that past people imagined alternative futures. A fruitful archaeological context for an exploration of past futures can be found in the choices people made during the late Iron Age and Roman period in Britain, which has an increasingly rich and high-resolution material record for complex changes and continuities during a period of cultural interactions and imperial power dynamics. More specifically, recent research into the architectural and material practices evident on rural settlement sites and across landscapes forces us to challenge pre-conceptions about the reactive/reactionary culture of rural societies. Case-studies from Kent and the West Country will be deployed to develop the argument that in the materialising of time, the future has a very significant part to play.
\end{abstract}

\section{Introduction}

While artefacts have object biographies, landscape is perhaps unique in its accretion of complexity, in ways which remain archaeologically visible. In this paper, we want to consider these biographical episodes from a temporal perspective, emphasising that new features and changes to a landscape resulted from projects for the future. We consider that meaning in landscape is always temporal and inhabiting a landscape necessitates engaging with past, present, and future. Any research focus on the temporality of landscape related to social significance and experience tends to prioritize the 'past in the past', probably because of the way that archaeologists often view the remains of the past as completed actions, which presents a theoretical difficulty in seeing the past future as full of possibility (cf. Adam 2009; Barbalet 1997: 118). Past and future are entwined in the course of action (Gosden 1994: 15-17), however, and we can nuance and strengthen our interpretations of past agency through a consideration of the different ways that people negotiated their relationships to the past and crafted their hopes, fears, and aspirations into plans for the future. The material manifestations of the past in the past exist for archaeologists to interpret, but reconstructing the future in the 
past presents some challenges. Social theorists, anthropologists, philosophers, and historians have demonstrated that the past, present, and future are inextricably linked, but identifying the future through archaeological remains is a complex matter where uncertainty is unavoidable. Nonetheless, if we reorientate the concern with continuity, repetition of actions, transformation of meanings and other temporally-contingent phenomena to try to understand how people were constructing their futures, we can expand and enhance our interpretations of the temporal facets of landscape.

Archaeologists relatively belatedly began to think around one of the key dimensions of their discipline, with time-concepts only beginning to be seriously debated in the 1980s (e.g. Shanks and Tilley 1987a, 1987b; cf. Holdaway and Wandsnider 2008; Lucas 2005). Time is now accepted as socially constructed and interpreting past ideas of time has become a key theme in archaeology. Multiple time scales can exist in a single society and the significance of cycles, rhythms, origins, events, horizons and other phenomena have been addressed in the last thirty years. Orientations to the future movements of the moon, sun, and planets as well as to the human lifecycle have received particular attention and been established as socially significant in a number of, mostly prehistoric, contexts (e.g. Gardner 2012; Lucas 2005; Olivier 1999; Murray 1999). There has also been considerable debate over the most appropriate timescales for archaeologists to work with (e.g. Bailey 2007; Harding 2005). Once established, a central topic in the archaeology of temporality became 'the past in the past'. Social memory, commemoration, forgetting, remembering to forget, fabricating memory, and so on, became significant themes in the 1990s, particularly amongst prehistorians and early Medievalists, including Richard Bradley and Howard Williams (e.g. Bradley 2002; Gosden 1994; Ingold 1993; Thomas 1996; Williams (ed.) 2003; Van Dyke and Alcock (eds) 2003). The relationship between temporality and the phenomenology of landscape is, perhaps, more apparent in the research of those working in prehistory, although a focus on monuments and the elite is shared by many of those examining temporality in the past (e.g. Davis 2007, Meskell 2003).

Among all period specialisations, the future has never featured prominently (though cf. Sassaman 2012 and Haskell and Stawski 2016). While 'the future' is rarely explicitly discussed in Roman-period archaeology, it is not hard to find: town-planning, deposition of hoards, votive offerings, and funerary monuments all contain obvious relationships to future action, while any building, boundary, road, or well was clearly constructed with the intention that it serve a purpose into the future. Indeed, the discussion of the past-in-the-past has always taken into 
account anticipation of the future, if not explicitly. Treatments of commemoration and monumentalization that include a consideration of the construction of future memory are more common amongst prehistorians, although any structure or activity that recalls the past in an enduring form is designed to function in the present and into the future. Such intentions of creation have implications for our interpretations of the roles of social memory, practice, and the transmission of ideas in the inhabitation of landscapes.

The classic account of the entwining of landscape and time remains Ingold's (1993) 'The temporality of the landscape', which emphasised the continual temporal movement of the present taskscape in which people dwell. Looking more to the past, Gosden and Lock's influential 1998 article 'Prehistoric Histories' formulated hypotheses about the difference between genealogical history and mythical history in prehistoric societies and noted that the step from acknowledging that history mattered to determining how it mattered is substantial. The process by which the narrative of the recent or distant past was understood, invented, preserved, and transmitted into the future was presented by Gosden and Lock as central to 'how' history mattered in the past. This discussion of the method by which memories and stories about the past were communicated itself tacitly implies that the narrator had chosen a way to ensure future memory in a society without a written record. The features in the landscape maintained and negotiated over time, which they discuss as manifestations of social relationships, were artefacts serving to create memories or, in other words, to ensure future remembering. While the oral transmissions that Gosden and Lock discuss are likely to remain hypothetical, the monuments and associations in landscape that reference the past and construct a physical reminder of it were features built with the intention of their duration into the future. Barrett (1999), alternatively, assumed a break with the knowledge and ideas of the distant past in the Iron Age of southern Britain, but he nonetheless discussed the significance of Bronze Age monuments and mythical origins to the creation of legitimacy, authority, and inheritance for future generations.

The notion that prehistoric people planned monuments to follow both long-term trajectories of development that resulted in the 'completed' project, as well as trajectories over shorter periods intended to transform or to culminate in destruction, provides another basis for considering the role of the future, especially in ritual landscapes (Bradley 2002). Through repeated practice and oral transmission, such intention could be communicated to successive generations, although it was likely to undergo substantial change over time. Significantly, such analysis of 
the relationship between past, present, and future in the biography of a monument demonstrates that places and landscapes can be used as evidence to study the experience and meaning of the future in ways that are not linked to astronomical/cosmological orientations or calendrical systems (cf. Ingold 1993). Without a record of past people's thoughts, understanding their values, perceptions, cognitions, and intentions will always rely (at least partly) on informed hypotheses, but analyses of this kind demonstrate the value of the pursuit.

The curation and transmission of memories of past experience are integrally connected to repetitive actions and constructing present futures. Oral histories, genealogies, narratives, explanations, and other knowledge transferred from one generation to the next, or even those re-invented without connection to past people, comprise only one aspect of the social connection between past, present, and future, however. Other significant examples of these temporal and social relationships include: decisions to maintain or build resilience and reduce vulnerability (i.e. during periods of economic, social, political, or environmental instability, volatility, and change); to plan for sustainability; to make interventions against unknown and/or unpleasant futures; to take advantage of new opportunities; to realign social networks, and so on. These and other examples constitute some of the motivations through which past people's agency in constructing the future can be explored. A complementary view of the integral relationship and interrelatedness between past, present, and future is proposed in Koselleck's (1985 [1979]) theoretical work (which, as Sassaman 2012 has argued, need not be restricted to the understanding of modernity). Koselleck suggested that 'experience' and 'expectation', as conceptual categories, encompass, and are more broad than, 'memory' or 'the past' and 'hope' or 'the future', respectively, and argued that these concepts are fundamental to a person's understanding and construction of temporal landscapes and how they can understand past and future constituted in the present (1985 [1979]: 256-8). Applying such a theory to the archaeology of landscape would enable a more complex interpretation of the present as constructed through any given person's experiences and expectations, which can be explored through a phenomenological study of the material remains. In turn, unpacking the relationship between past and future in a present moment can draw in other theoretical perspectives applicable at a range of archaeological scales. This is the direction this paper will take.

\section{The intersection of tense and experience}

By reflecting on the experience of being in the landscape as it relates to meaningful places as well as temporality, we can augment the typical phenomenological approach (e.g. Tilley 2004; 
cf. Hamilton and Whitehouse et al. 2006). Thinking thus about landscape as place and place as material culture aids our effort to capture the inherent dynamism of human agency and people's creative engagements with past and future. Dealing with 'the future' in the past or indeed the present is, however, a serious epistemological challenge, and we want to reflect a little more on the theoretical aspects of this here. The problem with the future, as noted already, is that it is not obviously 'real', but this is true of many other concepts that are nonetheless real in their consequences. Indeed, we might just as readily say that the past is not 'real'-as, indeed, notable philosophers of time such as George Herbert Mead have done (2002 [1932]; cf. Flaherty and Fine 2001), or perhaps rather that both past and future are only real in terms of their consequences for action in a given present. In this respect, they are like a whole range of other concepts whose importance is recognised in terms of their structuring effects on action, whether or not they are tangible in themselves (Mische 2009: 699; cf. Berger and Luckmann 1966: 1341). Even so, there is not a great deal of social theory to draw upon in trying to think about the future, as it is a neglected topic across most disciplines, except when rooted in mechanistic and teleological models of social function. Moreover, there is a legacy of 'temporal chauvinism' (Meskell 1999: 26) to deal with when we are looking at such issues in past societies, whose attitudes to the future are usually thought to be defined by cosmological concepts stressing fatalism and thus rigid conservatism (Adam 2009). While there is some truth in this characterization for the Roman world, there is arguably a distinction to be drawn between concepts of universal time and human destiny that comprise cosmologies, and more everyday notions of futures which are implicated in all actions.

How these intersect will be an important question, but we need to develop our understanding of the latter before we can proceed any further. Tackling the question of how futures impinge upon activity in a present moment is implicit in much of the theory concerned with social action, but has only recently attracted explicit attention. Notably, Barbara Adam, one of the leading sociological theorists of temporality (e.g. 1990), led a major research project called 'In Pursuit of the Future' just over a decade ago (http://www.cardiff.ac.uk/socsi/futures /project.html). Some of the outcomes from this, along with a small range of other studies building upon the phenomenological and pragmatist/interactionist traditions, give us tools to work with. Adam focuses on some of the broad trends in cultural attitudes to future time, crucially without consigning pre-modern concepts to the dustbin of history and rather showing (in contrast to early archaeological work on natural/cultural times) how different time-concepts mesh in different societies (Adam 2005; 2009; 2010; cf. Jenkins 2002). A more detailed 
breakdown of different aspects of futurity is provided by Ann Mische, who draws on phenomenologist Alfred Schutz as well as pragmatists Mead and John Dewey to create a typology of 'projectivity' (2009). Genealogically, these represent important branches of phenomenology and pragmatism neglected by archaeologists, but which have much to offer in the analysis of everyday life (e.g. Knoblauch 2014; cf. Gardner 2012). The dimensions of 'projectivity' which Mische identifies include: reach, breadth, clarity, contingency, expandability, volition, sociality, connectivity and genre (see Fig. 1) Together, these offer the potential for a nuanced understanding of the future dimension of action and its role in the constitution of situational human agency (cf. Barbalet 1997; Emirbayer and Mische 1998). A further, crucial ingredient in shaping our approach to the future is to consider how this aspect of temporality, in relation also to the past, impacts upon the construction of identities, as our first example below demonstrates. Not only is identity fundamentally temporal as well as comparative in character, but past and future are often in tension in characterising particular identity groupings, in relation to continuity and change (Jenkins 2002; Ybema 2010).

\section{Temporality and social change}

The examples we will use to explore the theme of the future in the past come from Roman Britain, a context within which there have been relatively few temporalized landscape studies (e.g. Cooper 2016; Eckardt et al. 2009; Gardner 2012; Kamash 2016; Wallace and Mullen 2019). Central to any discussion of temporality in Iron Age and Roman-period Britain are the often over-simplified and much-debated notions of cultural change and continuity, conventionally subsumed under the banner of the 'Romanization debate' (see e.g. Gardner 2013; Versluys 2014). Little has been said, however, of the relationship between the choice of individuals and groups to maintain traditions or make changes as a method of shaping their futures, whether or not the action resulted in the desired outcome. In earlier studies of late preRoman Iron Age and Roman-period Britain, traditional concepts of 'Romanization' espoused a view that urban and wealthy rural populations were open to change, whereas lower-status rural communities were conservative and maintained their ways of life in the face of changes happening to them (e.g. Haverfield 1905 (1923), Rivet 1958; cf. McCarthy 2013). Meanwhile, the focus of Roman-period research related to temporality is often on the monumental and highstatus manifestations of the manipulation of the past in the past (e.g. damnatio memoriae [e.g. Flower 2006, Varner 2004]), privileging urban elites. While providing excellent treatments of these contexts, these tend to recapitulate the outmoded cultural model to some degree. This is partly because such a perspective is also a reflection of modern stereotypes, which have only 
become more acute and divisive in the last few years as the urban/rural split has emerged as a major political fault-line (e.g. Brownstein 2016; Jennings et al. 2018). The influence of postcolonial theory has worked against these kinds of assumptions, but by looking at the manipulation of temporality, we can explore even further a new dimension of agency and the construction of identities, through the medium of landscape.

The rhythms and cycles of agricultural endeavours have an obvious future orientationsowing, breeding, processing, and so forth are undertaken in order to create a future benefit and the maintenance of ditches and other cyclical tasks prevent future problems. They both reflect a construction of time as a cycle of experience, wherein past, present and future are intimately connected (cf. Heidegger 1996 [1927]), but also a linear chain of actions and outcomes. Other practical actions - embellishment of or increasing the size of a dwelling, for example - may be undertaken in response to a past challenge or problem, but they also provide for a resolution in the present or future. This kind of practical planning and problem-solving was likely also related to ambitions and conceptualizations of the future that we can only conjecture, such as the increased prosperity of the next generation. Paradoxically, symbolic and ritual future-orientated actions can, perhaps, be better postulated. The construction of a funerary monument, for example, was presumably undertaken with a hope or ambition that the deceased persist into the future through the features and activities associated with it, and that the surviving family benefit from the communication of identity achieved through commemoration activities and the visibility of the monument. The social needs that were fulfilled through both practical and symbolic future-orientated shaping of landscape can augment interpretations of long-term change, experience, and agency.

Two case studies are presented below to explore how social theories of temporality intersect with the understanding of the rural landscape in the Late Iron Age and Roman periods in Britain. The first case study is in east Kent, where time and memory were manipulated to construct and communicate rural community identities, arguably to ensure future group cohesion in a time of rapid changes. A second case study on agency, futurity and farming in the upper Thames valley will examine evidence for agricultural rhythms and planning for the future. 


\section{Past and future landscapes in Kent}

Attempting to represent or reconstruct how past people without a written record perceived time and temporal change (cf. Haskell and Stawski 2017), materialized memory (cf. Mytum 2007), and embodied perception and cognition in the landscape with the presence and movement of their physical bodies (cf. Tilley 1994, following Merleau-Ponty 1962) can be approached through landscape survey data. Some features, through their clarity, lend themselves to such investigation, such as monuments, structures, and linear features (paths, roads, boundaries, etc.). Without the chronological specificity of excavation, survey data is of a lower resolution and interpretations must examine longer periods of time and larger-scale transformations.

As in studies centred on prehistory, it is possible to investigate the meaning of monuments and ritual to memory and temporality through Roman-period landscapes. Within the Roman-period southeast of Britain, however, the more pertinent questions of future action perhaps relate to how people used the landscape with respect to negotiating future relationships to Empire, ensuring future community cohesion, and anticipating the needs for both continuity and change. Through this case study, we intend to look at the development of a landscape, aspects of group activities, and how we can re-orientate interpretations of 'the past in the past' to understand what commemoration, repeated behaviours, and used of older features might mean for people's attitudes to the future, to continuity, and to change. This redirection of emphasis is a subtle shift in our thinking that can provide a linking step to developing an archaeology of future actions.

The Canterbury Hinterland Project has collected and synthesized a significant coverage of geophysical survey, aerial photographic and Lidar analysis, antiquarian observations, and more recent surface collection, metal-detecting and excavation in the area south and east of Canterbury, which can be used to address these issues (Wallace and Mullen 2019; Wallace et al. 2016). In brief, between 2011 and 2017, the project surveyed five areas using primarily gradiometry and micro-topograhical survey (covering c. 120ha) with some targeted areas of electrical resistance, ground-penetrating radar, and small-scale excavation and surface collection. The results have been compiled in a GIS along with interpretations of aerial photographs, satellite imagery, lidar anomalies covering the whole of east Kent. Digitisations of development-driven, research, and antiquarian excavation plans have also been incorporated along with Portable Antiquities Scheme data and Historic Environment Record data. 
The data are not complete, of course-Medieval, post-Medieval, and modern changes include villages, curated woodlands, dual carriageways, and so on that hinder both survey and phenomenological analysis. A phenomenological approach to understanding this landscape would traditionally call for the recording and analysing of a sensory experience of being in the landscape (cf. Hamilton and Whitehouse 2006 for a proposed methodology for conducting phenomenological research). Given the nature of the buried features and modern limitations, walking through as much of the area as possible has been complemented by GIS and visual models to approximate limited aspects of experience of place and 'being' in the landscape (cf. Eve 2014 and Haskell and Stawski 2017; such a method implicitly rejects the proposition, argued by Tilley 2008, that these tools are less effective than physically walking around the landscape). The results presented here place emphasis on viewsheds and intervisibility. A person's view as he or she moved along paths, trackways, and roads can be a rich source of data for analysing the creation and experience of landscape. Focussing on future-orientated effects of creating and using paths and trackways reveals possible planning to maintain continuity and anticipate change.

In this case study area, approximately $5 \mathrm{~km}$ southeast of Canterbury, the valley of the Nailbourne stream crosses the natural ridge that supported a likely pre-Roman route between Dover and Canterbury that later became the Roman-period road (Fig. 2). A likely Iron Age hilltop enclosure (Fig. 2, 'Nailbourne Iron Age enclosure') is situated south of and above the intersection of the ridge/road with the Nailbourne, perhaps serving as a point of control or pausing before descending from the ridge to cross the stream. A high-status Roman-period structural complex ('villa'—rare in this area; Fig. 2, 'Bourne Park "villa"') was constructed in the valley, further supporting the significance of power and status in this location. A trackway connects the Nailbourne enclosure to another likely Iron Age enclosure and one of the three possible Romano-Celtic temples in the area, at Bekesbourne. The trackway continues onto a nucleated settlement at Goodnestone before turning south to rejoin the ridge route/CanterburyDover road. A pathway running southwest from the likely Bekesbourne temple on the trackway extends perpendicular to the road, passing by another of the possible temples at Patrixbourne, across the road/ridge, into the valley, crossing the Nailbourne between two natural springs and the Bourne Park 'villa', up the opposite side of the valley, and (probably) onto the elevated position of three Roman-period burial mounds at Gorsley Wood (Fig. 2). The trackway and path reflected (and enabled) actions that brought people together, like worship or sacrifice, 
mourning, commemorating, and congregating for rural markets or fairs and can therefore be used to investigate the inscription and embodiment of group identities in the landscape. A brief demonstration of the application of this theoretical orientation follows below in an analysis of the experience of the landscape between the Roman-period burial mounds at Gorsley Wood (excavated in 1882/3, Vine 1883) and the likely Romano-Celtic temple at Bekesbourne (identified through CHP aerial photographic analysis), which were connected by a path (identified in the CHP magnetometry survey of Bourne Park and also through CHP aerial photographic analysis, see Wallace et al. 2016, Wallace and Mullen 2019).

Visibility analysis of what a viewer standing at the Gorsley Wood burial mounds could see reveals that the view from the mounds excluded the more quotidian sphere of the likely domestic structures within the valley (i.e. the 'villa'), giving greater emphasis through visibility to the location of the former Iron Age hilltop enclosure, the ridge/road, the three possible temples, and the nucleated settlement at Goodnestone (Fig. 3, lower left). People at the mounds could process time within the landscape with their own embodiment of it in a way that was not possible in areas of more reduced visibility, such as in the valley. Monuments of commemoration construct future memory and create a place for future ritual and memory reproduction, of course, but the meaning created by the visibility from this location also ensured the future social connections between the visible features and the group activities they hosted. By ascending to the site of the burial mounds and expanding the visible area, people increased the scope and quantity of available information, as well as their abilities to make visual and temporal connections across space. A link, therefore, may have existed between status (i.e. those who commemorated their dead in such monuments) and temporal significance of the landscape through the greater knowledge of the visual links in creating their perceptions of landscape and constructions of time and place within it.

The experience of using the path that connected the mounds to the Bekesbourne temple and the trackway provides another way to investigate how people anticipated and planned for the future, with reference to the past and in the context of group activities and ritual. Both visibility analysis, analysis of the digital elevation model, and physically walking along the part of the path within the geophysical survey area (Bourne Park) have been employed to produce the interpretations here. 
This path would have measured about $4.5 \mathrm{~km}$, but the descent from $100 \mathrm{~m}$ elevation at the Roman-period barrows, down to $30 \mathrm{~m}$ at the 'villa' and springs, back up to about $80 \mathrm{~m}$ at the road, down to $50 \mathrm{~m}$, and up to $60 \mathrm{~m}$ at the Bekesbourne temple (Fig. 2, inset lower left) required more than the time it would take to walk the same distance along a flat surface-which would be less than an hour at an average pace. There is a flatter, but more circuitous route (Fig. 2, inset lower left), so taking this path was a choice - a decision to leave aside other duties, sacrifice time, and expend greater effort. Following it, across the grain of the topography, perhaps to pause at the meaningful places along the way and look back, and to be aware of the expense of energy and time, was an aspect of what made following the path a significant activity.

The Roman-period burial mounds passed out of sight (Fig. 3, upper left) quite quickly after descending the slope into the valley. As one neared the crest of the valley on the side opposite the Gorsley Wood barrows, perhaps needing to pause after climbing just over half the slope, the path passed by two Bronze Age burial mounds (Fig. 3, upper right)—present today only as ring ditches in the geophysical results - twice the diameter of those Roman-period mounds across the valley, but perhaps much eroded in the millennium they had been standing ${ }^{i}$. It is also at this point along the path that the Gorsley Wood mounds came back into view, having been hidden by the brow of the hill until then. While the identities of the individuals potentially buried within them and the social structure that they represented undoubtedly passed beyond actual memory into the realm of myth and legend, the obscurity of their origins may have been a boon to those who wished to imbue them with social significance that served their needs in the present and the future (cf. Dark 1993, Meade 2004, Semple 2011, van Beek and der Mulder 2014).

By the design of the path to intersect downslope from these monuments, the visibility was restricted to highlight the path, valley, and Roman-period burial mounds and to increase the prominence of the Bronze Age barrows. The similarity of the mode of constructing burial monuments over a probably incomprehensible period of time entwined long-term pasts - and futures - and the short-term cycles of everyday life and practice. Through the path connecting these Bronze Age barrows and the Roman-period mounds, the community made reference to the older monuments and created a link between themselves and the land through the suggestion of community continuity from the deep past into the present and preserved as future memory by way of repeated activities of procession, commemoration, worship, and sacrifice 
formalized by the burial site, path, and temple. The local population may have been reaffirming the persistence of their place within this landscape as a method of increasing cohesion amongst this rural group, perhaps increasingly drawn towards new opportunities and social networks further afield (i.e. in the urban centres, across the Channel, etc.).

The path itself reinforces this meaning: by linking the 'new' mounds with people moving across the landscape down to the domestic enclosure in the valley, the space for the present and for living into the future is physically and symbolically linked to the space for the dead and for remembering, both through the visible linear feature and through the actions of the people. The way that the path passes between the natural springs and the 'villa' structures uses this temporal association to connect the work and leisure of home, the spirits of place and gateway to the supernatural represented by watery places, and the embodied practice of remembering those who have died. Because the path leads to a Romano-Celtic temple (the next point along the path from where the Roman-period burial mounds are visible after passing the Bronze Age barrows, Fig. 3), it also connects the future-oriented religious rituals of request, worship, and gratitude with the process of replicating memories. The path also led onto the trackway connecting people to the other likely Iron Age enclosures and the Goodnestone nucleated settlement, creating an enduring link to memory and group activities that would ensure community cohesion into the future. Connections like this across relatively large areas bring people together during the important moments of life, death, and worship that represent the cycle of the year and of the generations, all of which are embedded in this landscape. In this way, past experiences - the memory of the deceased, the cremation and burial ritual process, etc.-were made present and past occurrences (the 'mythological' or constructed cultural memory of the construction, use, and meaning of the Bronze Age barrows) were processed within a person's actions and embodiment of the landscape (cf. Koselleck 1985 [1979]: 261).

This analysis of the path and related features provides a way to interpret how people chose to, and were directed to, move through the landscape, planning for repeated and future incorporation of memory into the mind and body (cf. Connerton 1989). By anticipating repeated ritual activities and the future presence and movement of people, the inhabitants linked meaningful 'places' to action and to manipulations of the significance of the past, present, and the future. Rather than becoming entrenched in conservative practices and cementing an idealized construction of the past, these people were choosing new options for constructing a landscape imbued with meaning and complex relationships to time, endurance, 
belief, and group activities. By designing experiences focussed on places of power, status, and local cultural memory (i.e not reliant on or related to the road leading towards the urban centres), the rural community could strengthen their cohesion, which provided a way to ensure future relevance and their claim to the land.

In terms of Koselleck's paradigm, the visual connections, activities, and movement through the landscape cannot be extricated from the manipulation of temporality because they represent constructions of the present that rely on experience and expectation. Experience and expectation are directly represented in the material/monumental and indirectly reflected in the ephemeral embodiment of the landscape that can be interpreted from the pathway and visibility analyses. Consideration of the significance of landscape experience and anticipation in these terms provides greater scope for and complexity of interpretations than an exploration of ritual or 'the past in the past' alone.

\section{Making and breaking routines in the Upper Thames Valley}

Our second case-study area to use to explore these sorts of ideas is in the west of Roman Britain, in the region to the south of the Roman and later town of Cirencester. Like Canterbury, Cirencester became a major public town in the later 1 st and early 2 nd centuries $\mathrm{AD}$, and it too sits amidst a complex landscape, albeit with a considerable number of villas, particularly in the Cotswolds to the north. The upper Thames valley, to the south of the town, is perhaps better understood from modern excavation, though, as this region has seen much more developerfunded archaeology in recent years. Oxford Archaeology have published a number of sites in this region, and these give us detailed evidence for rural lifeways that we can use as a basis for thinking about how concepts of past and future were entwined in the materiality of place. Among the best known are Cotswold Community, excavated from 1999 to 2004, and Claydon Pike, dug from 1979 to 1983 (Figs. 4, 5; Miles et al. 2007; Powell et al. 2010). In terms of the typology of futurity discussed by Ann Mische, perhaps the most straightforward aspects to address with this sort of evidence are reach, breadth, contingency, expandability, and connectivity. We can also certainly talk about the concept of the 'recurrence' of the past into the future on a number of levels.

This concept is embedded in significant ways in the rhythms of agricultural life that we can capture a general flavour of across Late Iron Age and Roman Britain. Indeed, the dominance 
of cyclical temporal orderings of activity in the growing of crops and the rearing of livestock is perhaps one reason why rural lifeways are often regarded as less progressive than those of urban-dwellers with a seemingly more 'linear' temporality. While we can certainly problematize those assumptions, there is a considerable body of research on the architectural and other evidence from later Prehistory, and from across Britain, which emphasises the profound entanglement of agricultural cycles and almost all aspects of living in rural settlements. Whether considering the practical and metaphorical associations of different spaces within a roundhouse, and their orientation within enclosures, or these enclosures themselves and the trackways which connected them, there seem to be recurrent patterns. These link seasonal activities and repeated routines of movement, to associations with light and dark, life and death, and growth and decay, which seem all-pervasive (Chadwick 2004; 2016; Giles and Parker Pearson 1999; McCarthy 2013; Taylor 2013; Williams 2003). The repetition of many agricultural practices manifests a series of attitudes to the future based upon reproduction of what was done in the past to secure the continuation of food production, minimising risk and entailing perhaps another set of cyclical concepts to do with reciprocity, in terms of the social relationships connecting inter-dependent communities (Grey 2011). In terms of longer-term scenarios, the aspect of rural life which has perhaps most preoccupied researchers is tenure and the continuity of households (e.g. Smith 1997), which is indeed a major concern of contemporary farming families revealed in sociological studies (Gill 2013). The evidence for routines, risk-aversion, and actively maintained continuity_and therefore a perhaps limited reach and breadth of futurity - is certainly readily detectible on the Romano-British farmsteads in the upper Thames valley. For example, many of the enclosure boundaries at both sites mentioned exhibit characteristic signs of repeated maintenance, recutting, and minor adjustments along established lines (e.g. Trench 29, phase 3 (mid-Roman) at Claydon Pike; Fig. 6). The environmental evidence gives the clearest indications of the usual cycles of plant growth and processing, or animal breeding and management - the inhabitants of Claydon Pike seem to have focussed on haymaking in the mid-Roman period while at Cotswold Community there was a mixed arable and pastoral regime, each with their own temporal sequences (Miles et al. 2007: 165; Powell et al. 2010: 118, 142; cf. Lodwick 2017). More social cycles, perhaps relating to regular festivals as well as the bonds of reciprocity, are indicated by evidence in the faunal assemblage for feasting at Claydon Pike (Miles et al. 2007: 163). All of these features might be interpreted as emphasising a predictable and repetitive future orientation. 
This, however, is not the whole story, and other framings of the future are manifest in different aspects of these places as material culture. Most clearly, these are visible at points of disjuncture in the site sequences. While these might readily be ascribed to a whole host of factors, there are some consistent patterns across the sites in the region that indicate that there were certain periods when decisions had to be made that represented at least a partial break with the past, and therefore a different conception of the future. At the same time, there are forms of evidence that suggest that people sought to reinforce the predictability of the future in what we would call the religious domain, and perhaps that this was more pronounced at times of uncertainty. In relation to the first of these themes, while the Roman conquest of this part of Britain in the $40 \mathrm{~s}$ AD is not detectible on the average rural site, there are more widespread episodes of change in the early-mid 2nd century, the end of the $3 \mathrm{rd} /$ beginning of the 4 th century, and around the end of the 4th century (Miles et al. 2007: 373-403). These periods are generations apart, but what happens in each of them is a significant change to the materialisation of places and suggests that different futures could certainly be envisaged and acted upon than those manifest in the normal flow of life. These are evident in major changes to settlement organisation and architecture at both Cotswold Community and Claydon Pike (Miles et al. 2007: 159-65, 206-9; Powell et al. 2010: 119, 164). It is hard to avoid the conclusion that these periods of change were fundamentally linked to developments in Cirencester, and that therefore the introduction of an urban-rural dynamic into Britain was more important than anything singularly 'Roman'. While the different communities were thoroughly inter-connected, their distinct rhythms and temporalities were equally significant, and perhaps created boundaries of identity (indeed, there is some evidence this was manifest in personal adornment, Miles et al. 2007: 345). The demands of the town population for foodstuffs - for both humans and animals - and migration of people to join this population as it developed in the early 2nd century created opportunities - new futures - and perhaps tensions for the rural population to the south (Powell et al. 2010: 142-3). This duality is evident later on, too, when sites like those highlighted here were drawn into the coin-based economy in the 4th centuryitself indicative of a change in futures embedded in different systems of exchange - only to be exposed to greater risk when the coin supply stopped at the beginning of the 5th century (Miles et al. 2007: 397). What future people envisaged then-when economic structures but perhaps not cultural ones were radically transforming around them-is vital to understanding the end of Roman Britain. 
The scale of economic disruption at the end of the 4th century and beginning of the 5th century is a hotly contested topic and the evidence from our sites is mixed. Certainly, Cotswold Community seems to have been abandoned at this time, but the excavators suggest that the inhabitants may simply have moved to Cirencester, which is one of the Roman towns with a case for continuity into the 5th century (Powell et al. 2010: 166). In earlier periods of uncertainty, other mechanisms for controlling the future may have off-set the risks associated with changing the agricultural focus or the settlement organisation of these communities. At Cotswold Community, mid-Roman burials were placed into long-standing boundary features, while in the late Roman phase burials were associated with a still-visible Bronze Age barrow (Powell et al. 2010: 136-8, 165). At Claydon Pike, 'ritual' features include a possible sheepburial foundation deposit in the new early $2^{\text {nd }}$-century aisled building, and an enclosure which may have been a small shrine. The later Roman revamping of the same site to a more conventional villa was accompanied, a generation later, by the building of a more definitive circular shrine, while inhumations also took place in established boundaries (Miles et al. 2007: 163-4, 208-9). Just as we saw in the Kent case-study, seeking to control the past is really about the future, and all of these features can be seen in the same light, taking us into the notions of volition and connectivity in Mische's scheme. Returning also to Barbara Adam's discussion of cultures with an emphasis on fate, this can be detected in a good deal of Roman religious practice, which had whole priesthoods devoted to finding out what the future held for people (Adam 2005; cf. Graham 2006: 125-148). Equally, though, widespread evidence of the kinds of practices mentioned here shows how people sought to influence the future, whether or not they believed that influence was mediated by other entities. In this, and every other aspect of the archaeology of these rural settlements, we can see just how much of the materialisation of landscape is imbued with ideas about temporality, in particular the relationships between past and future.

\section{Conclusion: the new temporalities of landscape}

The two case-studies presented in this paper highlight distinct but interlocking aspects of the materialisation of time in particular places. In viewing place as material culture, we are seeking to join up some of the disparate approaches to past experience of landscape with biographical perspectives on sites and artefacts and studies of the involvement of objects in the shaping of identities. The architecture-broadly defined - of settlements, and their situation in relationship to other features in a landscape, are important parts of the temporal orientation of 
the people who constructed and lived in these places. Together with movement along the pathways which connected them, these were all practices which both took time and made time. We see the understanding of more everyday routines, and their transformation, as contributing to a broader phenomenological project than that which flourished in the 1990s and early 2000s (cf. Brück 2005). Partly, this comes from integrating typical domestic sites, of the sort in which the majority of people in Roman Britain lived, with more monumental features like barrows. It also involves the enfolding of neglected strands of phenomenological theory into archaeological practice, where the work of Alfred Schutz, for example-who reversed Husserl's bracketing out of everyday life to construct his phenomenological sociology—might hold considerable potential to resolve some of the acknowledged problems with the approach (Barber 2018; Brück 2005; Johnson 2008: 137-163; Johnson 2012; Moran 2016). Conceptions of the future can certainly be made more central to our interpretations in this way.

Furthermore, such considerations can yield fresh insights into the political dimensions of complex social changes like those occurring in Roman Britain. Especially in a context like this, the political dynamics of imperialism and the introduction of an urban/rural relationship require us to interrogate the evidence carefully, as both of these relationships involve contested timeconcepts (cf. Cornell 2015; Nanni 2011). While some aspects of Roman-period temporal experience are understood quite exhaustively from written evidence in terms of their basic calendrical components, and some of their religious significance (e.g. Feeney 2007; Salzman 1990), their wider cultural and political implications are only beginning to be explored (e.g. Gardner 2012; Hannah 2015). This brings us back to the centrality of temporality to our understanding of situated past human agency. We have emphasised the necessity of thinking about the future dimension of this process because it is particularly important in understanding how people act 'in their time', and because stereotypes about conservatism and creativity are easy to fall into. Such stereotypes are all-pervasive in our own time, and increasingly relevant as we debate an unexpectedly lively 21 st century. Once we start to consider how the diaphanous notion of 'the future' shapes everything we do, it is hard to escape the conclusion that it is the most important tense. While seeing the past from the present is unavoidable, we need to identify our own temporal preconceptions and try to re-imagine the future from the perspective of a person walking across the Bourne Park landscape, or recutting a ditch at Cotswold Community. By redirecting our perceptions of past time concepts and producing such future-orientated interpretations, we can augment our approaches to agency and intentionality, advance our 
understanding of past landscape experience, and contribute to more complex and nuanced narratives of social continuity and change.

\section{Acknowledgements}

This article has developed out of two papers. The first was aired at the 'Shapes of Time: Recurrence in Material Culture' colloquium (University of East Anglia, October 2017) and we warmly thank the organizers, Anastasia Moskvina and Sarah Cassell for including us. The second version was delivered in the 'Futures of the Past' session that the authors co-organized with Ben Jervis at the Theoretical Archaeology Group conference (Cardiff, December 2017). We thank the participants and discussants in both sessions for their thought-provoking questions and comments. We would also like to thank the editor, and anonymous referees, for their very helpful comments on an earlier version of this paper.

Andrew Gardner, UCL Institute of Archaeology, andrew.gardner@ucl.ac.uk Lacey Wallace, University of Lincoln, lwallace@lincoln.ac.uk

\section{References}

Adam, B., 1990. Time and Social Theory. Cambridge: Polity Press.

Adam, B., 2005. Futures told, tamed and traded. In Pursuit of the Future Project Working Paper 4; http://www.cardiff.ac.uk/socsi/futures/briefings.html\#working. Accessed 18/8/17.

Adam, B., 2009. Future matters: challenge for social theory and social inquiry. In Pursuit of the Future Conference Paper 32; http://www.cardiff.ac.uk/socsi/futures/briefings .html\#conference. Accessed 20/9/17.

Adam, B., 2010. History of the future: paradoxes and challenges. Rethinking History 14(3), $361-378$.

Barbalet, J.M., 1997. The Jamesian theory of action. Sociological Review 45(1), 102-121.

Barber, M., 2018. Alfred Schutz, in The Stanford Encyclopedia of Philosophy, ed. E.N. Zalta. https://plato.stanford.edu/archives/spr2018/entries/schutz/. Accessed 11/9/18.

Barrett, J. 1999. The mythical landscape of the British Iron Age, in Archaeologies of Landscape: contemporary perspectives, eds. W. Ashmore and A.B. Knapp. Oxford: Blackwell Publishers, 253-265.

Berger, P. and Luckmann, T., 1966. The Social Construction of Reality. London: Penguin. 
Bradley, R., 2002. The Past in Prehistoric Societies. London: Routledge.

Brownstein, R., 2016. How the election revealed the divide between city and country. The Atlantic, November 17 2016. https://www.theatlantic.com/politics/archive/2016/11/ clinton-trump-city-country-divide/507902/. Accessed 10/9/18.

Brück, J., 2005. Experiencing the past? The development of a phenomenological archaeology in British prehistory. Archaeological Dialogues 12(1), 45-72.

Chadwick, A.M., 2004. Heavier burdens for willing shoulders? Writing different histories, humanities and social practices for the Romano-British countryside, in TRAC 2003: Proceedings of the Thirteenth Annual Theoretical Roman Archaeology Conference, Leicester 2003, eds. B. Croxford, H. Eckardt, J. Meade and J. Weekes. Oxford: Oxbow Books, 90-110.

Chadwick, A.M., 2016. Foot-fall and hoof-hit. Agencies, movements, materialities and identities; and later prehistoric and Romano-British trackways. Cambridge Archaeological Journal 26(1), 93-120.

Connerton, P., 1989. How Societies Remember. Cambridge: Cambridge University Press.

Cooper, A., 2016. Other types of meaning: relationships between round barrows and landscapes from 1500 BC-AC 1086. Cambridge Archaeological Journal 26(4): 66596.

Cornell, P., 2015. Colonial encounters, time, and social innovation, in Rethinking Colonialism: comparative archaeological approaches, eds. C.N. Cipolla and K.H. Hayes. Gainesville: University Press of Florida, 99-120.

Dark, K.R., 1993. Roman-period activity at Prehistoric ritual monuments in Britain and in the Armorican Peninsula, in Theoretical Roman Archaeology: First Conference Proceedings, ed. E. Scott. Aldershot: Avebury, 133-46.

Davis, J.L., 2007. Memory groups and the state: erasing the past and inscribing the present in the lanscapes of the Mediterranean and Near East, in Negotiating the Past in the Past: Identity, Memory, and Landscape in Archaeological Research, ed. N. Yoffee. Tucson: University of Arizona Press, 227-56.

Eckardt, H., Brewer, P., Hay, S. and Poppy, S., 2009. Roman barrows and their landscape context: a GIS case-study at Bartlow, Cambridgeshire. Britannia 40, 65-98.

Emirbayer, M. and Mische, A., 1998. What is agency? American Journal of Sociology 103(4), 962-1023.

Eve, S., 2014. Dead Men's Eyes: embodied GIS, Mixed Reality and landscape archaeology. Oxford: BAR British Series 600. 
Feeney, D., 2007. Caesar's Calendar: ancient time and the beginnings of history. Berkeley: University of California Press.

Flaherty, M.G. and Fine, G.A., 2001. Present, past, and future: conjugating George Herbert Mead's perspective on time. Time and Society 10(2/3), 147-161.

Gardner, A., 2012. Time and empire in the Roman world. Journal of Social Archaeology 12(2), $145-166$.

Gardner, A., 2013. Thinking about Roman imperialism: post-colonialism, globalisation and beyond? Britannia 44, 1-25.

Gell, A., 1992. The Anthropology of Time: cultural constructions of temporal maps and images. Oxford: Berg.

Giles, M. and Parker Pearson, M., 1999. Learning to live in the Iron Age: dwelling and praxis, in Northern Exposure: interpretative devolution and the Iron Ages in Britain, ed. B. Bevan. Leicester: University of Leicester, 217-231.

Gill, F., 2013. Succession planning and temporality: the influence of the past and the future. Time and Society 22(1), 76-91.

Gosden, C., 1994. Social Being and Time. Oxford: Blackwell.

Gosden, C. and Lock, G., 1998. Prehistoric Histories. World Archaeology 30(1), 2-12.

Graham, M.W., 2006. News and Frontier Consciousness in the Late Roman Empire. Ann Arbor: University of Michigan Press.

Grey, C., 2011. Constructing Communities in the Late Roman Countryside. Cambridge: Cambridge University Press.

Hamilton, S., Whitehouse, R., Brown, K., Combes, P., Herring, E. and Seager Thomas, M., 2006. Phenomenology in practice: towards a methodology for a 'subjective' approach. European Journal of Archaeology 9(1), 31-71.

Hannah, R., 2015. Theorization, measurement, and standardization of calendrical time. Oxford Handbooks Online, DOI: 10.1093/oxfordhb/9780199935390.013.90.

Harding, J. 2005. Rethinking the Great Divide: Long-Term Structural History and the Temporality of the Event. Norwegian Archaeological Review 38(2): 88-101.

Haskell, D.L. and Stawski, C.J., 2017. Re-envisioning Tarascan temporalities and landscapes: historical being, archaeological representation, and futurity in past social processes. Journal of Archaeological Method and Theory 24(2), 611-39.

Heidegger, M., 1996 [1927]. Being and Time. Translated by J. Stambaugh. Albany: State University of New York Press. 
Holdaway, S. and Wandsnider, L., 2008. Time in Archaeology: an introduction, in Time in Archaeology: time perspectivism revisited, eds. S. Holdaway and L. Wandsnider. Salt Lake City: University of Utah Press, 1-12.

Ingold, T., 1993. The temporality of the landscape. World Archaeology 25(2), 152-74.

Jenkins, R., 2002. In the present tense: time, identification and human nature. Anthropological Theory 2(3), 267-280.

Jennings, W., Stoker, G. and Warren, I., 2018. Towns, cities and Brexit. The UK in a Changing Europe, 11 February 2018. http://ukandeu.ac.uk/towns-cities-and-brexit/. Accessed $10 / 9 / 18$

Johnson, D.P., 2008. Contemporary Sociological Theory: an integrated multi-level approach. New York: Springer.

Johnson, M., 2012. Phenomenological approaches in landscape archaeology. Annual Review of Anthropology 41, 269-284.

Kamash, Z., 2016. Memories of the past in Roman Britain, in The Oxford Handbook of Roman Britain, eds. M. Millett, L. Revell and A. Moore. Oxford: Oxford University Press, 681-696.

Knoblauch, H., 2014. Projection, imagination, and novelty: towards a theory of creative action based on Schutz, in The Interrelation of Phenomenology, Social Sciences and the Arts (Contributions to Phenomenology 69), eds. M. Barber and J. Dreher. New York: Springer, 31-49.

Koselleck, R., 1985 [1979]. Futures Past: On the semantics of historical time. Translated by K. Tribe. Cambridge, MA: MIT Press.

Lodwick, L.A., 2017. Agricultural innovations at a late Iron Age oppidum: archaeobotanical evidence for flax, food and fodder from Calleva Atrebatum, UK. Quaternary International 460, 198-219.

Lucas, G., 2005. The Archaeology of Time. London: Routledge.

McCarthy, M., 2013. The Romano-British Peasant: towards a study of people, landscapes and work during the Roman occupation of Britain. Oxford: Windgather press.

Mead, G.H., 2002 [1932]. The Philosophy of the Present. Amherst: Prometheus Books.

Meade, J., 2004. Prehistoric landscapes of the Ouse Valley and their use in the Late Iron Age and Romano-British period, in TRAC 2003: Proceedings of the Thirteenth Annual Theoretical Roman Archaeology Conference, Leicester, 3-6- April 2003, eds. B. Croxford, H. Eckardt, J. Meade, and J. Weekes. Oxford: Oxbow Books, 78-89.

Merleau-Ponty, M., 1962. Phenomenology of Perception. London: Routledge \& Kegan Paul. 
Meskell, L., 2003. Memory's materiality: ancestral presence, commemorative practice and disjunctive locales, in Archaeologies of Memory, eds. R. van Dyke and S.E. Alcock. Malden, MA: Blackwell, 34-55.

Meskell, L., 1999. Archaeologies of Social Life. Oxford: Blackwell.

Miles, D., Palmer, S., Smith, A. and Perpetua Jones, G., 2007. Iron Age and Roman Settlement in the Upper Thames Valley: excavations at Claydon Pike and other sites within the Cotswold Water Park. Oxford: Oxford Archaeology.

Mische, A., 2009. Projects and possibilities: researching futures in action. Sociological Forum 24(3), 694-704.

Moran, D., 2016. Continental philosophies, in The Oxford Handbook of Archaeological Theory, eds. A. Gardner, M. Lake and U. Sommer. DOI: 10.1093/oxfordhb/9780199567942. 013.034.

Murray, T. 1999. Introduction. In Time and Archaeology, ed. T. Murray. London: Routledge, $1-7$.

Mytum, H., 2007. Materiality and memory: an archaeological perspective on the popular adoption of linear time in Britain. Antiquity 81, 381-96.

Nanni, G., 2011. Time, empire and resistance in settler-colonial Victoria. Time and Society 20(1), 5-33.

Olivier, L. 1999. The Hochdorf 'princely' grave and the question of the nature of archaeological funerary assemblages, in Time and Archaeology, ed. T. Murray. London: Routledge, 109-138.

Powell, K., Smith, A. and Laws, G., 2010. Evolution of a Farming Community in the Upper Thames Valley: Excavation of a Prehistoric, Roman and post-Roman Landscape at Cotswold Community, Gloucestershire and Wiltshire. Vol. 1. Oxford: Oxford Archaeology.

Thomas, J., 1996. Time, Culture and Identity: an interpretive archaeology. London: Routledge.

Salzman, M.R., 1990. On Roman Time: the Codex-Calendar of 354 and the rhythms of urban life in Late Antiquity. Berkeley: University of California Press.

Sassaman, K.E., 2012. Futurologists look back. Archaeologies 8(3), 250-68.

Semple, S., 2011. Perceptions of the Prehistoric in Anglo-Saxon England: Religion, Ritual, and Rulership in the Landscape. Oxford: Oxford University Press.

Shanks, M. and Tilley, C., 1987a. Social Theory and Archaeology. Cambridge: Polity Press.

Shanks, M. and Tilley, C., 1987b. Abstract and substantial time. Archaeological Review from Cambridge 6(1), 32-41. 
Smith, J.T., 1997. Roman Villas: a study in social structure. London: Routledge.

Taylor, J., 2013. Encountering Romanitas: characterising the role of agricultural communities in Roman Britain. Britannia 44, 171-190.

Tilley, C., 2008. Phenomenological approaches to landscape archaeology, in Handbook of Landscape Archaeology, eds. B. David and J. Thomas. Walnut Creek, CA: Left Coast Press, 271-84.

Tilley, C., 2004. Round barrows and dykes as landscape metaphors. Cambridge Archaeological Journal 14(2), 185-203.

Beek, R. van, and Mulder, G. der, 2014. Circles, cycles and ancestral connotations. The longterm history and perception of late Prehistoric barrows and urnfields in Flanders (Belgium). Proceedings of the Prehistoric Society 80, 299-326.

Van Dyke, R.M. and Alcock, S.E., (eds) 2003. Archaeologies of Memory. Oxford: Blackwell.

Versluys, M.J., 2014. Understanding objects in motion. An archaeological dialogue on Romanization. Archaeological Dialogues 21(1), 1-20.

Vine, F. 1883. On three Roman tumuli in Gorsley Wood, near Bridge and Canterbury. Archaeologia Cantiana 15, 311-317.

Wallace, L. and Mullen, A. (2019, First View). Landscape, Monumentality, and the Expression of Group identities: an exploration of Iron Age and Roman east Kent. Britannia 50.

Wallace, L., Mullen, A., Johnson, P., and Verdonck, L. 2016. Archaeological Investigations at Bourne Park, Bishopsbourne. Archaeologia Cantiana 137, 251-280.

Williams, H., (ed.) 2003. Archaeologies of remembrance: death and memory in past societies. New York: Kluwer.

Williams, M., 2003. Growing metaphors: the agricultural cycle as metaphor in the later prehistoric period of Britain and North-Western Europe. Journal of Social Archaeology $3(2), 223-255$.

Ybema, S., 2010. Talk of change: temporal contrasts and collective identities. Organization Studies 31(4), 481-503.

\section{List of Illustrations}

Figure 1. Aspects of 'projectivity' (Adapted from Mische 2009: 699-701).

Figure 2. Case study area in east Kent showing a selection of Iron Age and Roman-period evidence. (NB: polygons representing features are exaggerated with thickened outlines here to make them more visible at this scale.) Inset upper right: location of area within east Kent. Inset lower left: comparison of the surface elevation profiles of the path (top) and a hypothetical 
alternative path along the valley (bottom) (horizontal scale as shown, height exaggerated $\mathrm{x} 5$ for clarity); A: Gorsley Wood Roman-period burial mounds; B: Nailbourne stream between natural springs and 'villa' buildings; C: Canterbury-Dover road; D: Bekesbourne RomanoCeltic temple and trackway. (Lacey Wallace and Chris Blair-Myers with Kent Historic Environment record data and background DEM data, Crown copyright/database right 2017, an Ordnance Survey/EDINA supplied service.)

Figure 3. Visibility analyses of the same area as shown in Fig. 2 (see Fig. 2 for key, labels, and scale). Visible areas are approximate as modern features and the $5 \mathrm{~m}$ pixels (using OS Terrain 5) limit precision. (Lacey Wallace and Chris Blair-Myers with background DEM data, Crown copyright/database right 2017, an Ordnance Survey/EDINA supplied service.)

Figure 4. General location map of area surrounding Cirencester in the Roman period; Cotswold Community and Claydon Pike circled (Miles et al 2007: 374, with additions; (C) Oxford Archaeology, used with permission).

Figure 5. Mid-Roman site phases at Cotswold Community and Claydon Pike (Powell et al. 2010: 120; Miles et al. 2007: 94; (C) Oxford Archaeology, used with permission).

Figure 6. Successive ditched enclosure cuts/recuts at Claydon Pike (Miles et al. 2007: 117; (C) Oxford Archaeology, used with permission).

\section{Author Bios}

Andrew Gardner is Senior Lecturer in the Archaeology of the Roman Empire at the UCL Institute of Archaeology. His publications include An Archaeology of Identity: Soldiers and Society in Late Roman Britain (2007) and Evolutionary and Interpretive Archaeologies: a Dialogue (edited with Ethan Cochrane, 2011); he is currently working on a monograph on Roman Britain. His research interests are centred upon the social dynamics of Roman imperialism, the nature of frontier cultures, and the ways in which people in different societies understand time.

Lacey Wallace is a Senior Lecturer in Roman History and Material Culture at the University of Lincoln and her research interests focus on social questions related to urbanism, rural settlement, and landscape. She currently directs a landscape survey project in Kent (Canterbury Hinterland Project) and was previously a Research Associate in Roman Archaeology at the University of Cambridge where she coedited and contributed to Thwing, Rudston, and the Roman-Period Exploitation of the Yorkshire Wolds (2017). Lacey was awarded her from Cambridge in 2011 and used her doctoral work to produce her 2014 book, The Origin of Roman London.

\footnotetext{
${ }^{i}$ There is evidence for more than 2 per square kilometre, which would be a high density in an open landscape and which, therefore, is all the more significant in an area of villages, wooded areas, and other coverage that often prevents the identification of such features.
} 


\begin{tabular}{|l|l|}
\hline Reach & Short/ middle/ tong-term scenarios \\
\hline Breadth & Range of possible futures \\
\hline Clarity & Degree of elaboration of imagined futures \\
\hline Contingency & Fixed/pre-determined ws. malleable/uncertain \\
\hline Expandability & Possibilities opening or narrowing \\
\hline Wolition & Passiwe / active; future moving towards us, or vice wersa \\
\hline Sociality & Social relationships in imagined futures \\
\hline Connectivity & Underlying logic of temporal links - agency / causality/deter mination \\
\hline Genre & Narrative mode of projectivity - comedy or tragedy? Utepian? \\
\hline
\end{tabular}




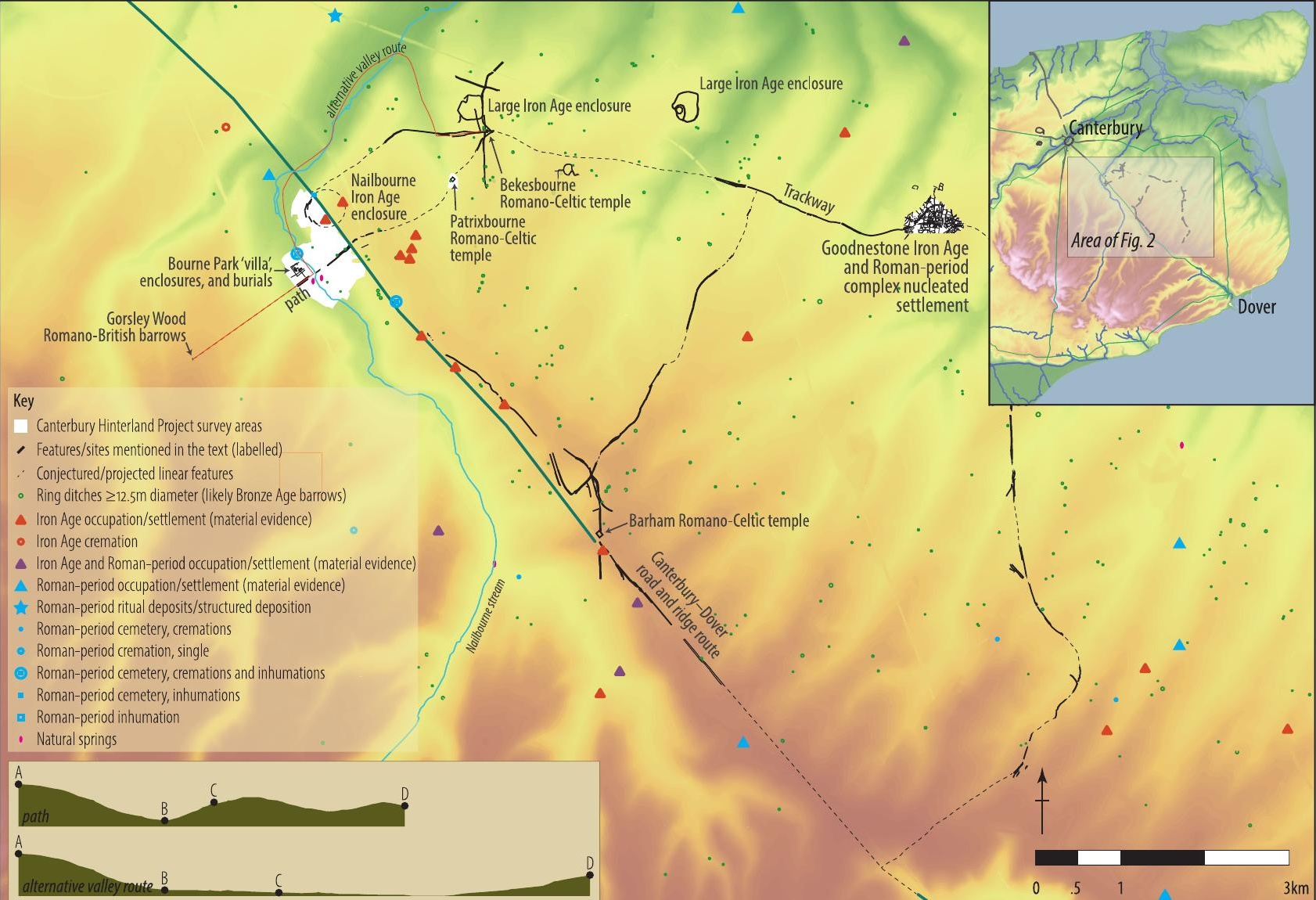




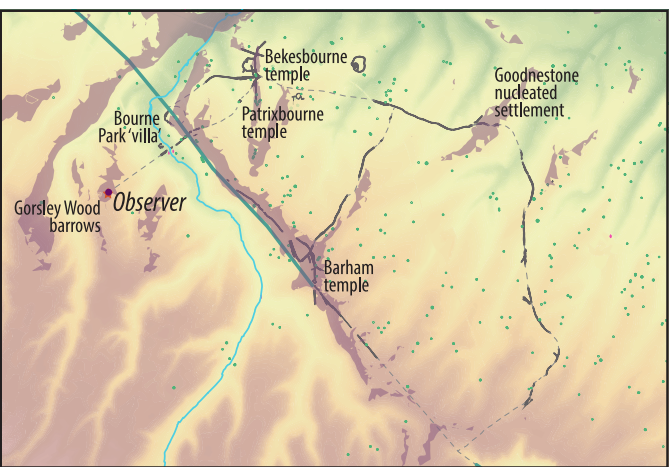

Area from which the Gorsley Wood barrows would be visible to a $1.8 \mathrm{~m}$ person (at estimated height of $5 \mathrm{~m}$ for the largest barrow, derived from the diameter and assumption that they took the common flat-topped conical form).

Ground surface visible to a 1.8m person standing at the point labelled 'observer', the location of the two large Bronze Age barrows on the Gorsley Wood-Bekesbourne temple path. (NB: buffer not shown, but the top $3 m$ of the largest Gorsley Wood barrow would have been visible from this point; $(f$. top-left image.)

Ground surface visible to a $1.8 \mathrm{~m}$ person standing beside (east of) the Gorsley Wood barrows at the point labelled 'observer'. 


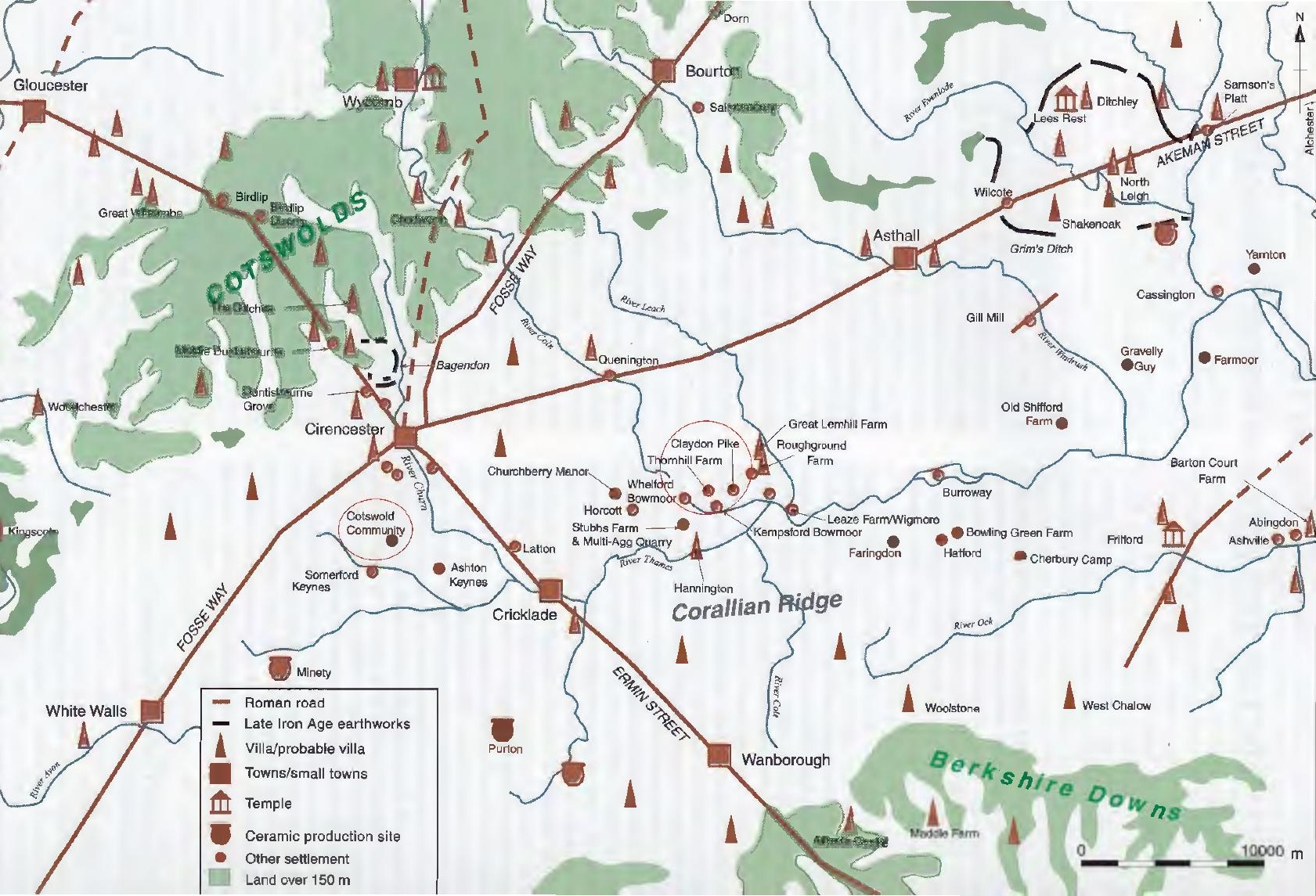



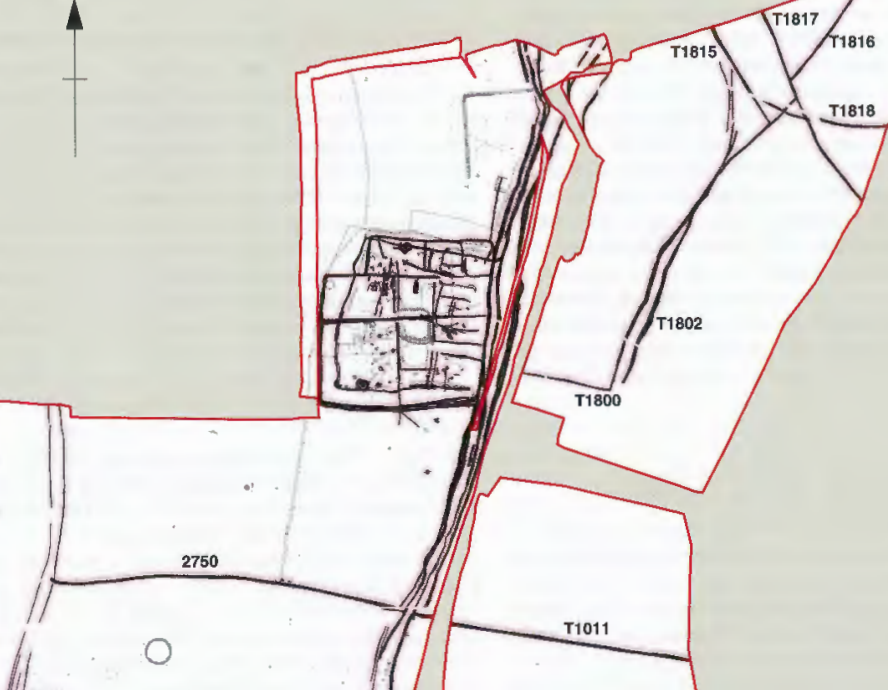

\section{9}

Burial 6683

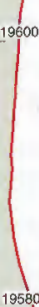

0

2750
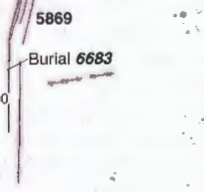

Burial 7717

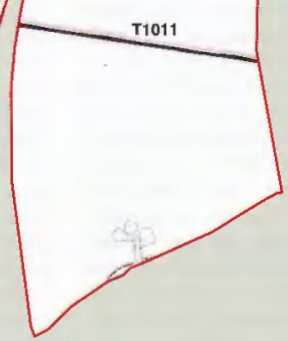




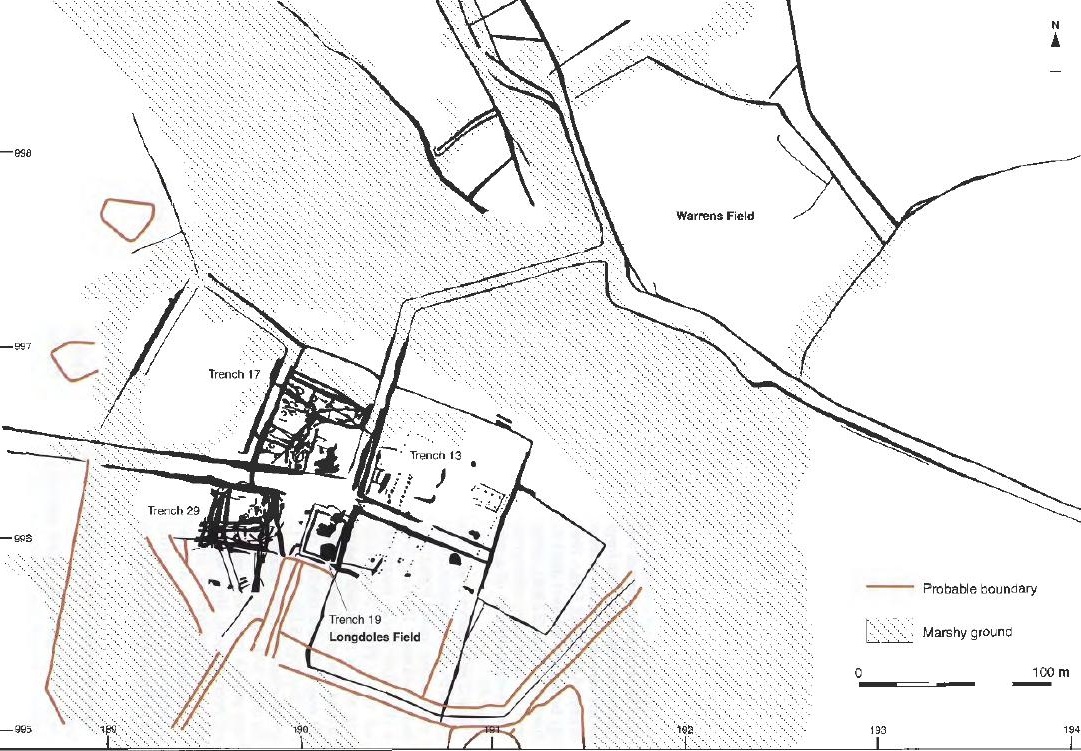




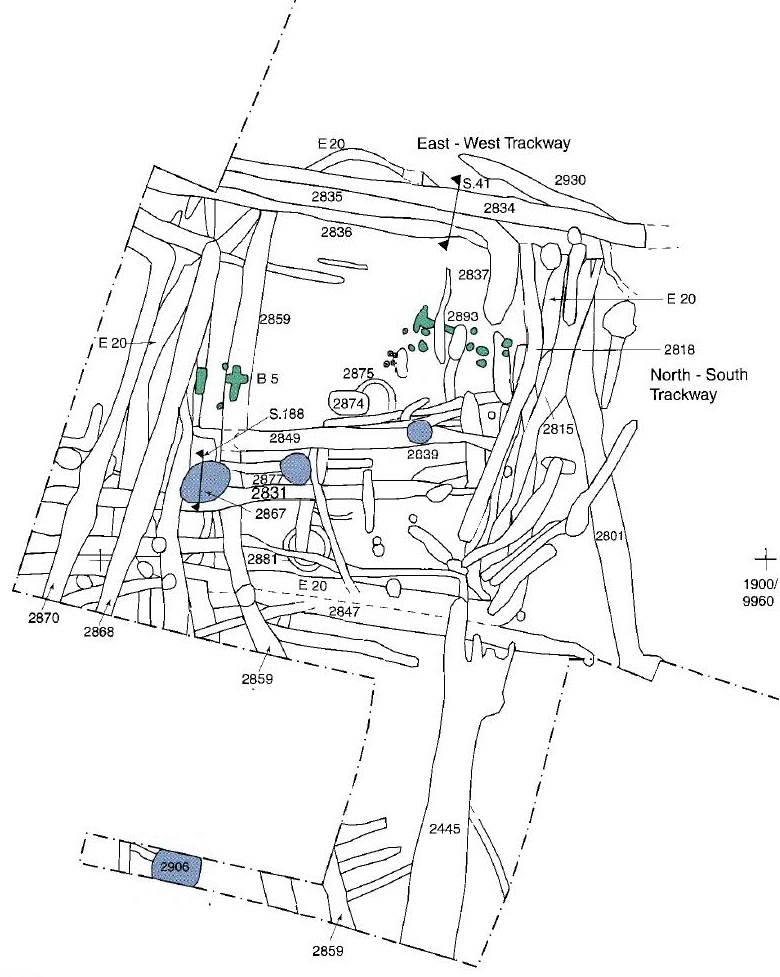

\section{Waterhole}

